\title{
Short-wavelength enrichment of polychromatic light enhances human melatonin suppression potency.
}

\author{
George Brainard \\ Thomas Jefferson University \\ John P. Hanifin \\ Thomas Jefferson University \\ Benjamin Warfield \\ Thomas Jefferson University \\ Marielle K. Stone \\ Thomas Jefferson University \\ MôlolWthilamangsadditional works at: https://jdc.jefferson.edu/neurologyfp \\ Thomas Jefferson University \\ Part of the Neurology Commons

\section{Let us know how access to this document benefits you} \\ See next page for additional authors
}

\section{Recommended Citation}

Brainard, George; Hanifın, John P.; Warfield, Benjamin; Stone, Marielle K.; James, Mary E.; Ayers, Melissa; Kubey, Alan; Byrne, Brenda; and Rollag, Mark, "Short-wavelength enrichment of polychromatic light enhances human melatonin suppression potency." (2015). Department of Neurology Faculty Papers. Paper 82.

https://jdc.jefferson.edu/neurologyfp/82

This Article is brought to you for free and open access by the Jefferson Digital Commons. The Jefferson Digital Commons is a service of Thomas Jefferson University's Center for Teaching and Learning (CTL). The Commons is a showcase for Jefferson books and journals, peer-reviewed scholarly publications, unique historical collections from the University archives, and teaching tools. The Jefferson Digital Commons allows researchers and interested readers anywhere in the world to learn about and keep up to date with Jefferson scholarship. This article has been accepted for inclusion in Department of Neurology Faculty Papers by an authorized administrator of the Jefferson Digital Commons. For more information, please contact: JeffersonDigitalCommons@jefferson.edu. 


\section{Authors}

George Brainard, John P. Hanifin, Benjamin Warfield, Marielle K. Stone, Mary E. James, Melissa Ayers, Alan Kubey, Brenda Byrne, and Mark Rollag 


\section{Full Published Citation:}

Brainard GC, Hanifin JP, Warfield B, Stone M, James M, Ayers M, Kubey A, Byrne $B$, and Rollag $M$. Short wavelength enrichment of polychromatic light enhances human melatonin suppression potency. $J$ Pineal Res 2015; 58:352361.

*If interested in obtaining the published PDF version of this article, please contact the corresponding author below.*

\section{Short Wavelength Enrichment of Polychromatic Light Enhances Human Melatonin Suppression Potency}

George Brainard, John Hanifin, Benjamin Warfield, Marielle Stone, Mary James, Melissa Ayers, Alan Kubey, Brenda Byrne, and Mark Rollag

Department of Neurology, Thomas Jefferson University, Philadelphia, PA 19107

Running title: Blue Light Enhances Melatonin Suppression

${ }^{*}$ Corresponding author

George C. Brainard, Ph.D.

Suite 507, 1025 Walnut Street

Department of Neurology,

Thomas Jefferson University

Philadelphia, Pennsylvania 19107

Email: george.brainard@jefferson.edu

Phone: 215-955-7644

Fax: 215-923-7588

Key words: Light, Blue, Fluorescent, Melatonin, Photoreception, Melanopsin, Circadian 


\section{Abstract}

The basic goal of this research is to determine the best combination of light wavelengths for use as a lighting countermeasure for circadian and sleep disruption during space exploration, as well as for individuals living on Earth. Action spectra employing monochromatic light and selected monochromatic wavelength comparisons have shown that short wavelength visible light in the blue-appearing portion of the spectrum is most potent for neuroendocrine, circadian, and neurobehavioral regulation. The studies presented here tested the hypothesis that broad spectrum, polychromatic fluorescent light enriched in the short wavelength portion of the visible spectrum is more potent for pineal melatonin suppression in healthy men and women. A total of 24 subjects were tested across three separate experiments. Each experiment used a within-subjects study design that tested eight volunteers to establish the full-range fluence-response relationship between corneal light irradiance and nocturnal plasma melatonin suppression. Each experiment tested one of three types of fluorescent lamps that differed in their relative emission of light in the short wavelength end of the visible spectrum between 400 and $500 \mathrm{~nm}$. A hazard analysis, based on national and international eye safety criteria, determined that all light exposures used in this study were safe. Each fluence-response curve demonstrated that increasing corneal irradiances of light evoked progressively increasing suppression of nocturnal melatonin. Comparison of these fluence-response curves supports the hypothesis that polychromatic fluorescent light is more potent for melatonin regulation when enriched in the short wavelength spectrum. 


\section{Introduction}

Light is a powerful stimulus for regulating human circadian, neuroendocrine and neurobehavioral responses [1-3]. Light also has the capacity to restore human health in clinical applications such as treating winter depression and selected sleep disorders. In addition, light therapy has been evaluated for healthy individuals who experience problems associated with intercontinental jet travel, shift work and space flight [1-6].

Neural signals conveying information about environmental light are transmitted from the retina through the retinohypothalamic tract to the hypothalamic suprachiasmatic nuclei (SCN) [7]. In turn, the SCN transmit information about lighting and circadian time to the pineal gland where the hormone melatonin is synthesized [8]. As a result, daily patterns of light exposure entrain the circadian secretion of melatonin. In most vertebrate species studied, this pattern results in higher levels of melatonin during the dark, nighttime hours. In addition, exposure to light of sufficient intensity, wavelength and duration can acutely suppress high nocturnal melatonin secretion from the pineal gland [9-11]. Once released into the blood vascular system, melatonin is known to be a pluripotent hormone that modulates the circadian system at the level of the SCN as well as numerous peripheral tissues $[8,12]$. Since melatonin is lipophilic, it readily transfers into all other body fluids [8]. Recent evidence from sheep has supported the theory that an important route of the delivery of the melatonin signal to brain tissue is directly from the pineal gland into the cerebrospinal fluid of the third ventricle $[13,14]$. 
In the past 15 years, there have been fundamental advances in the understanding of photoreceptive input to the circadian and neuroendocrine systems of humans and other mammals. In 2001, two human analytic action spectra identified 446-477 nm as the most potent wavelength region for melatonin suppression $[10,11]$. Those data indicated that a novel ocular photosensory system, distinct from the visual rods and cones, is primarily responsible for regulating melatonin in humans. Based on selected monochromatic wavelength comparisons, further human studies indicated that circadian phase-shifting, and autonomic stimulation, as well as the acute effects of light on alertness and vigilance are shifted towards the shorter wavelength, or blue-appearing, part of the spectrum [15-22].

Seminal discoveries have elucidated the basic anatomy and physiology of the photosensory system that supplies input to the circadian and neuroendocrine systems. It is clear that a small population of widely dispersed retinal ganglion cells is directly responsive to light and projects to the suprachiasmatic nuclei as well as regulatory nuclei in the central nervous system [23,24]. These intrinsically photosensitive retinal ganglion cells (ipRGCs) have an expansive arbor of dendrites that form a "photoreceptive net" for circadian phototransduction [25]. The ipRGCs contain melanopsin, a vitamin A photopigment that mediates phototransduction in these cells [26]. Although light detection for circadian, neuroendocrine and neurobehavioral responses is mediated principally by the ipRGCs, studies on genetically manipulated rodents [27-30], normal monkeys [31], and humans [15,20,32], clearly demonstrate that the visual rod and cone photoreceptors also have a role in modulating this physiology.

The goal of the research presented here is to determine the best combination of light wavelengths for use as a lighting countermeasure for circadian and sleep disruption during space exploration, as well as for individuals living on Earth. The specific hypothesis tested in the following studies is that broad spectrum fluorescent light enriched in the short wavelength portion of the visible spectrum will be more potent for the regulation of pineal melatonin secretion in healthy men and women. The data 
demonstrate a fluence-response relationship between melatonin suppression and corneal light irradiances for each of three types of fluorescent light. Comparison of these fluence-response curves supports the hypothesis that polychromatic fluorescent light is more potent for melatonin regulation when enriched in the short wavelength spectrum.

\section{Materials and Methods}

\section{Hazard Analysis}

Since exposure to ultraviolet radiation or intense visible light within the range of $400 \mathrm{~nm}$ to $550 \mathrm{~nm}$ can induce damage the eye, an assessment of the three lighting systems used in this research was necessary $[33,34]$. An independent hazard analysis based on guidelines set by the American Conference of Governmental Industrial Hygienists (ACGIH) and the International Commission on Non-lonizing Radiation Protection (ICNIRP) was performed to ensure that subjects were not at risk for photochemical retinal injury. All measurements of the experimental light panels were taken at $30 \mathrm{~cm}$, the typical viewing distance of the panels in the study. The primary analysis was completed using three instruments: 1) a Fieldspec Hand-held Spectroradiometer manufactured by Analytical Spectral Device (Boulder, CO), Model \#FSHH 325-1075, for all spectroradiometer measurements; 2) a radiometer/photometer (Model 1400BL, International Light Technologies, Inc., Newburyport, MA) with a silicon-diode detector head (Model \#SEL033), a wide angle output optic (W\#11437) and a filter (Y\#27475) to provide photopic illuminance response; and 3) a Minolta Luminance Meter (nt-1), Model LS-100 (Japan), to measure the panel luminance as a cross-check of the spectroradiometric radiance measurements at $30-70 \mathrm{~cm}$. Measurements of each panel also were made with an ultraviolet detector head using an International Light Model 1400 A Radiometer with Model SEL240 (\#3682) and Model SEL033 (\#3805) detector (with input Optic W\#6874 and Filter UVA \#28246) to assure that no hazardous UV radiation was emitted from the surface of the light panel.

\section{Study design}

In each of three studies, eight subjects completed a within-subjects fluence-response experiment that tested nine light irradiances of polychromatic lamplight and one dark 
exposure control night for nocturnal melatonin suppression. The three test lamplights were standard white light 4,000 K fluorescent, prototype blue-enriched white 17,000 K fluorescent, and prototype strongly enriched blue (SEB) fluorescent.

\section{Subjects}

The healthy females $(\mathrm{N}=12)$ and males $(\mathrm{N}=12)$ in these studies had a mean \pm SEM age of $24.3 \pm 0.4$, had a mean wake up time of $07: 49 \mathrm{~h}+/-8 \mathrm{~min}$, and signed an approved IRB consent document before participating. All subjects demonstrated normal color vision by both the Ishihara and Farnsworth Munsell D-100 color vision tests (mean \pm SEM score of $83.8 \pm 67.2$ ). All subjects were in good ocular and physical health as assessed by a neurophthalmologist, good mental health as assessed by a clinical psychologist, and free of signs of substance abuse as determined by urinary toxicological screens. Ten days prior to entry into the protocol, subjects were confirmed for sleep-wake stability with routine bedtime starting at midnight ( \pm 30 minutes) as ascertained by actigraphy (Octagonal Sleepwatch, AMI, Ardsley, NY), filling out daily sleep-wake logs and confirming wake and bed times by calling into a voice mailbox.

\section{Light exposure protocol}

Subject pre-experimental adaptation began in the laboratory at 18:00h. During this period, subjects stayed upright in chairs engaging in reading, studying, or conversation and were not permitted to sleep. Light levels did not exceed 10 lux at eye level in any direction of gaze. As described elsewhere, each experiment began at midnight when subjects were blindfolded and remained awake and sitting upright in darkness for 120 min [10]. While blindfolded, a blood sample was taken just prior to 02:00h and subjects were then exposed to a $90 \mathrm{~min}$ light stimulus from $02: 00 \mathrm{~h}$ to $03: 30 \mathrm{~h}$. Before experimental light exposures, blindfolds were removed. Subjects' pupils were not dilated in this study. During light exposure, each subject sat quietly with their eyes open and facing a $119 \times 120 \mathrm{~cm}$ flat panel of fluorescent lights with their eyes $30 \mathrm{~cm}$ from the central portion of the light-emitting surface. The light was patternless and provided full retinal field exposure. At 03:30h, a second blood sample was taken. Each subject was 
exposed to complete darkness from $02: 00 \mathrm{~h}$ to $03: 30 \mathrm{~h}$ on their control night and was tested with at least 6 days between each nighttime exposure.

\section{Light production and measurement}

Polychromatic light stimuli were produced by equipment donated by Philips Lighting (Netherlands). Test lamps were white 4,000 K fluorescent lamps (TL5 HO 54W/830), prototype blue-enriched white $17,000 \mathrm{~K}$ fluorescent lamps, and prototype SEB fluorescent lamps housed in Strato Luminaires (Model TPH 710) containing high-speed electronic ballasts. Each luminaire was electronically dimmable down to $40 \mu \mathrm{W} / \mathrm{cm}^{2}$. An additional neutral density filter panels were used to further adjust the intensity of the light levels below $40 \mathrm{uW} / \mathrm{cm}^{2}: 0.3 \mathrm{ND}$ (0.3 optical density; 50\% transmittance), $0.6 \mathrm{ND}$ (0.6 OD; 25\% transmittance) and $0.9 \mathrm{ND}$ (0.9 OD; 12.5\% transmittance) (Rosco Laboratories, Stamford, CT). Spectroradiometric and photon flux assessments of the wavelengths at the level of subjects' corneas were done with a portable spectroradiometer with a fiber optic sensor (ASD, Boulder, CO, FieldSpec Model \#FShh 325-1075P). The spectral power distributions of the lamplights are shown in Figure 1. Routine measurement of the light irradiance $\left(\mu \mathrm{W} / \mathrm{cm}^{2}\right)$ was done with International Light Radiometer/Photometer 1400A (Newport, MA) with an SEL033 \#6857 detector head with an F \#23102 filter and cosine correction. All spectroradiometric and radiometric equipment was calibrated annually with a standard lamp traceable to NIST. Light irradiances and illuminances were measured at volunteers' eye level immediately before and after the $90 \mathrm{~min}$ exposure. Additional spot measures were taken with a $1^{\circ}$ luminance meter (Minolta Camera Co. LTD., Japan, \#301749) each half hour of the exposure to ensure stimulus stability. For each fluence-response study, intensities ranged over a four log unit photon flux range of $10^{10}$ to $10^{14}$ photons $/ \mathrm{cm}^{2}$. 

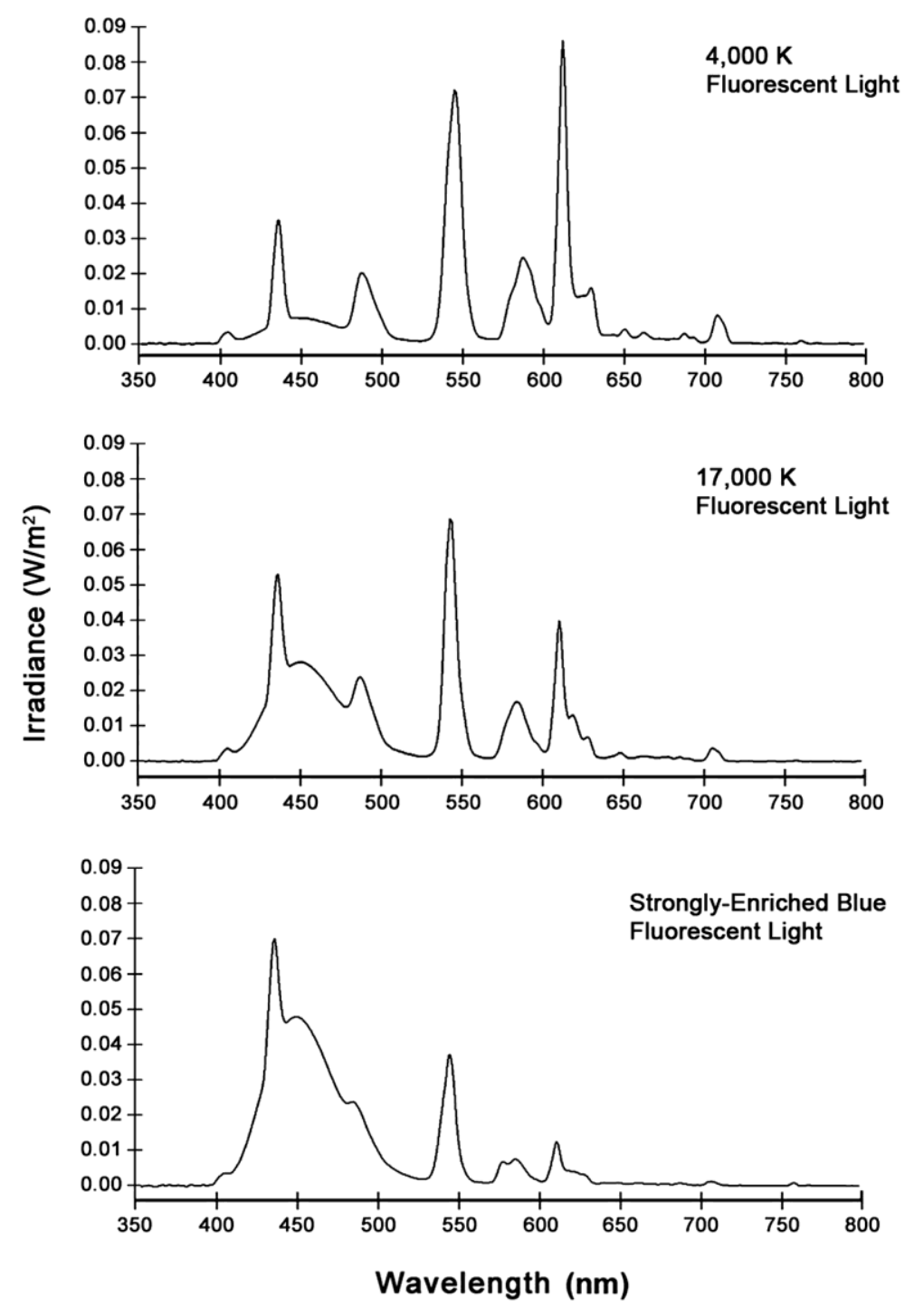

Fig. 1. These graphs show the SPD of the polychromatic light sources. The top SPD is from a standard white fluorescent lamp (4000 K CCT). The middle SPD graph is from a prototype white appearing, blueenriched lamp (17,000 K CCT). The bottom SPD is from aprototype SEB lamp. CCT, correlated color temperature; SEB, strongly enriched blue; SPD, spectral power distribution.

\section{Melatonin assay}

As detailed elsewhere, radioimmunoassy (RIA) was used to assay plasma for melatonin $[10,35]$. Duplicate $200 \mu \mathrm{l}$ aliquots of each unknown and control sample were extracted into chloroform. Then chloroform was removed by centrifugation, samples were resuspended in assay buffer, washed twice with petroleum ether and evaporated to dryness. Samples then were resuspended with deionized water, incubated for $48 \mathrm{hr}$ with 
radiolabeld ligand and $\mathrm{R} 1055$ antiserum, precipitated by centrifugation and radioactivity was quantified [10,35]. This RIA had a minimum detection limit of $0.5-2.0 \mathrm{pg} / \mathrm{mL}$.

\section{Calculation of effective rod, cone and melanopsin photoreceptor illuminances}

To calculate human rod, cone and melanopsin photoreceptor illuminances, the lamp SPDs entered into a toolbox worksheet that is a software model for human photoreception freely available online [36]. The SPDs for the experiments shown here were imported into the worksheet in $1 \mathrm{~nm}$ increments between 378 and $782 \mathrm{~nm}$. Per toolbox instructions, all raw negative SPD values were changed to zero.

\section{Statistics}

Two-tailed, Students' $t$-tests were used to assess significance of raw melatonin change from $02: 00 \mathrm{~h}$ to $03: 30 \mathrm{~h}$. Raw melatonin data were then converted to \% melatonin change scores and \% control-adjusted change scores as described elsewhere [10]. Sets of pre-exposure melatonin values and \% control-adjusted melatonin change scores were analyzed with one-way, repeated measures ANOVA. Significant differences between groups were assessed with post-hoc Fisher PLSD test with alpha of 0.05 . The fluence-response curve for light exposures were calculated and fit using Origin 8.0 (OriginLab Corp., Northhampton, MA). The curves were fit to an unconstrained parametric model with the melatonin response $(Y)$ to the corneal irradiance $(X)$ is predicted by: a theoretical initial $Y$-response for the curve $\left(A_{1}\right)$; the theoretical final $Y$ response ("infinite" dose) for the curve $\left(A_{2}\right)$; the dose producing a response halfway between $A_{1}$ and $A_{2}\left(X_{50}\right)$; and the slope estimator for the curve between $A_{1}$ and $A_{2}(p)$. These compose the equation:

$$
Y=\frac{A_{1} A_{2}}{1+\left(X / X_{50}\right)^{p}}+A_{2}
$$

The curve was tested for fit of the data by coefficient of correlation $\left(R^{2}\right)$. 


\section{Results}

Based on national and international safety criteria, the hazard analysis determined that all intended study exposures used in this study were safe [33,34]. The radiance measurements did not exceed the long-term limit of $10 \mathrm{~mW} /\left(\mathrm{cm}^{2} \cdot \mathrm{sr}\right)$. Spectral weighting of the $4,000 \mathrm{~K}, 17,000 \mathrm{~K}$ and SEB spectral power distributions with the blue-light hazard or $B(\lambda)$ function provided a maximum effective blue-light radiance value of $0.0094,0,061$, and $0.41, \mathrm{~mW} /(\mathrm{cm} 2 \cdot \mathrm{sr})$, respectively. Thus, the SEB panel, the most blue-enriched of the three fluorescent panels, was less than $5 \%$ of the ACGIH and ICNIRP limits $[33,34]$.

Selected light stimuli characteristics (corneal irradiances, photon fluxes and illuminances) are provided in Table 1 along with measured mean pupil sizes and calculated mean retinal irradiances.

Table 1. Selected target corneal irradiances, measured corneal illuminances, corneal photons (380760nm), measured pupil sizes and calculated retinal irradiances of light stimuli.

\begin{tabular}{cccccc}
\hline \hline $\begin{array}{c}\text { Fluorescent } \\
\text { Stimulus }\end{array}$ & $\begin{array}{c}\text { Corneal } \\
\text { Irradiance } \\
\left(\mu \mathrm{W} / \mathrm{cm}^{2}\right)\end{array}$ & $\begin{array}{c}\text { Corneal } \\
\text { Illuminance } \\
\text { (lux })\end{array}$ & $\begin{array}{c}\text { Photon Flux } \\
\left(\text { photons } / \mathrm{cm}^{2} / \mathrm{s}\right)\end{array}$ & $\begin{array}{c}\text { Mean } \\
\text { Pupil } \\
\text { Diameter } \\
(\mathrm{mm})\end{array}$ & $\begin{array}{c}\text { Calculated Retinal } \\
\text { Irradiance } \\
\left(\mu \mathrm{W} / \mathrm{cm}^{2}\right)\end{array}$ \\
\hline $4,000 \mathrm{~K}$ & 734 & 2,874 & $2.03 \times 10^{15}$ & 2.72 & 4.24 \\
$4,000 \mathrm{~K}$ & 40 & 135 & $1.14 \times 10^{14}$ & 4.19 & 0.54 \\
$4,000 \mathrm{~K}$ & 11 & 23 & $2.64 \times 10^{13}$ & 4.72 & 0.19 \\
$17,000 \mathrm{~K}$ & 800 & 2,511 & $1.84 \times 10^{15}$ & 3.02 & 5.90 \\
$17,000 \mathrm{~K}$ & 25 & 71 & $4.45 \times 10^{13}$ & 4.33 & 0.37 \\
$17,000 \mathrm{~K}$ & 10 & 27 & $1.78 \times 10^{13}$ & 4.83 & 0.18 \\
Strong Blue & 1500 & 2,397 & $3.28 \times 10^{15}$ & 2.28 & 6.38 \\
Strong Blue & 58 & 91 & $6.71 \times 10^{14}$ & 3.39 & 0.52 \\
Strong Blue & 10 & 13 & $1.16 \times 10^{13}$ & 4.74 & 0.18 \\
\hline
\end{tabular}


ANOVA demonstrated a significant effect of light on pupil diameter for the $4,000 \mathrm{~K}$ exposures $(F=118.3, d f=8, p<0.0001)$, the $17,000 \mathrm{~K}$ exposures $(F=102.4, d f=8$, $\mathrm{p}<0.0001)$, and the SEB exposures $(\mathrm{F}=104.0, \mathrm{df}=8, \mathrm{p}<0.0001)$. The Fisher PLSD test showed that pupil diameters were significantly larger when exposed to the lowest (1 through $18 \mu \mathrm{W} / \mathrm{cm}^{2}$ ) versus higher (40 through $734 \mu \mathrm{W} / \mathrm{cm}^{2}$ ) 4,000 K irradiances. For the $17,000 \mathrm{~K}$ exposures, pupil diameters were significantly larger with the lowest $(1,5$, and $10 \mu \mathrm{W} / \mathrm{cm}^{2}$ ) versus higher irradiances (20 through $800 \mu \mathrm{W} / \mathrm{cm}^{2}$ ). Finally, for the SEB exposures, pupil diameters were significantly larger with the lowest (0.8 and 4 $\mu \mathrm{W} / \mathrm{cm}^{2}$ ) versus higher irradiances (6 through $\left.1500 \mu \mathrm{W} / \mathrm{cm}^{2}\right)$.

The top graph in Figure 2 compares mean (+ SEM) pre- and post-plasma melatonin values for each study night from the $4,000 \mathrm{~K}$ light exposures. All irradiances at or above $1 \mu \mathrm{W} / \mathrm{cm}^{2}$ significantly suppressed melatonin $(p<0.05$ to $p<0.005)$. Percent controladjusted melatonin change scores presented in the bottom graph of Figure 2 showed a significant effect of light irradiance on melatonin suppression $(F=13.24, d f=8, p<0.0001)$. Increasing irradiances of 4,000 K light exposure evoked progressively larger melatonin suppressions. The Fisher PLSD test showed that higher irradiances of $4,000 \mathrm{~K}$ light (734 and $274 \mu \mathrm{W} / \mathrm{cm}^{2}$ ) elicited significantly stronger melatonin suppression than irradiances at or below $80 \mu \mathrm{W} / \mathrm{cm}^{2}$. The $80 \mu \mathrm{W} / \mathrm{cm}^{2}$ irradiance of $4,000 \mathrm{~K}$ light elicited a significantly stronger melatonin suppression than lower irradiances $(8.34,3.81$, and 1 $\mu \mathrm{W} / \mathrm{cm}^{2}$ ), while 39.5 and $18 \mu \mathrm{W} / \mathrm{cm}^{2}$ elicited significantly stronger melatonin suppression than the lowest irradiance of $0.8 \mu \mathrm{W} / \mathrm{cm}^{2}$. 


\section{4,000 K Fluorescent Light}
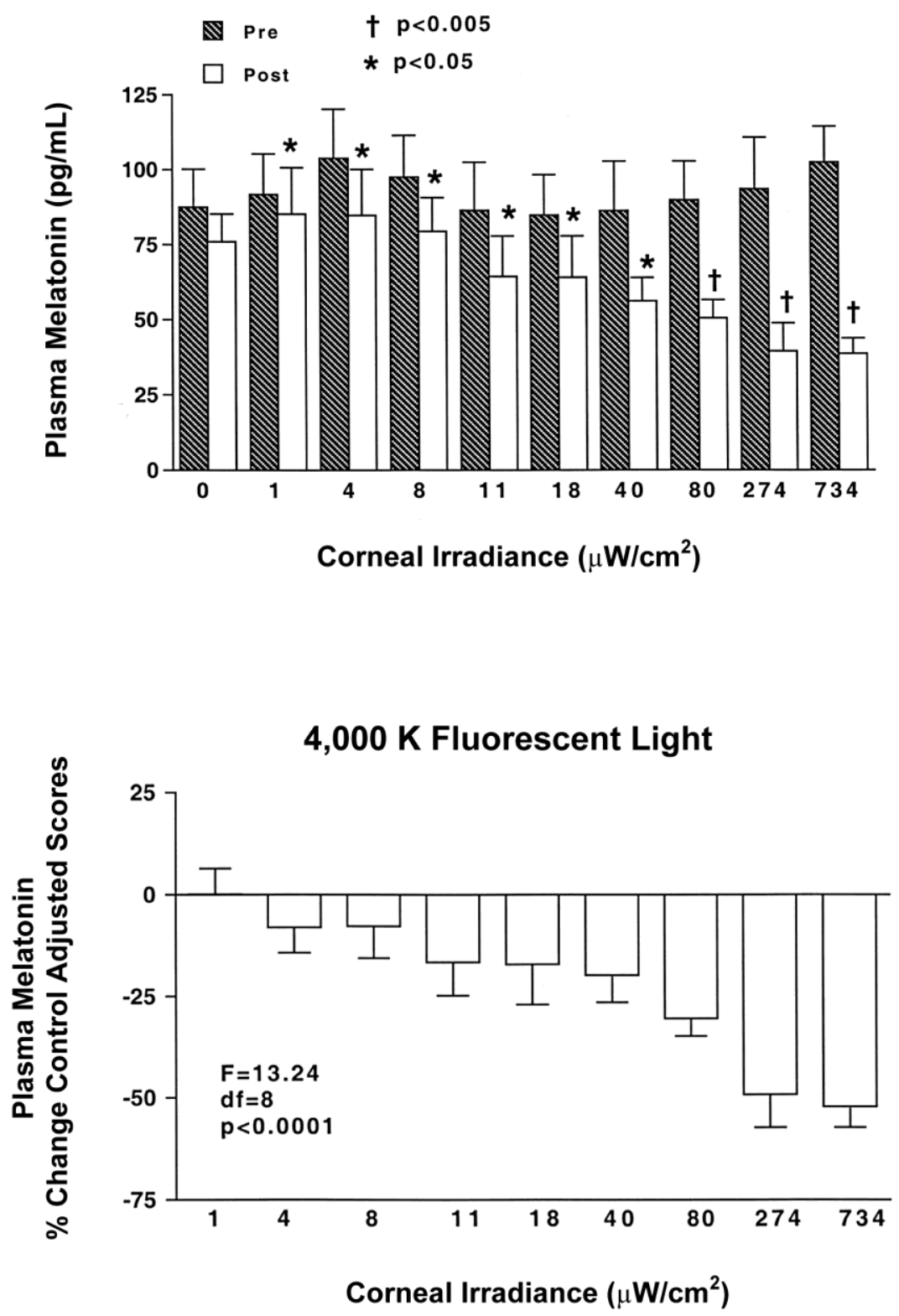

Fig. 2. The top graph compares the mean (+ S.E.M.) pre- and postplasma melatonin values for the 4000 $\mathrm{K}$ light exposures. Percent control-adjusted melatonin change scores from these data are presented in the bottom graph. 
For the $17,000 \mathrm{~K}$ light exposures, comparison of the mean pre- and post-plasma melatonin values shows that all corneal irradiances at or above $15 \mu \mathrm{W} / \mathrm{cm}^{2}$ significantly suppressed melatonin $(p<0.05$ to $p<0.005)$. For the $17,000 \mathrm{~K}$ light exposures, percent control-adjusted melatonin change score showed that there was a significant effect of light irradiance on melatonin suppression $(F=12.48, d f=8, p<0.0001)$. Increasing irradiances of $17,000 \mathrm{~K}$ light evoked progressively larger melatonin suppressions. Fisher PLSD tests showed that the $800 \mu \mathrm{W} / \mathrm{cm}^{2}$ corneal irradiance elicited significantly stronger melatonin suppression than irradiances at or below $50 \mu \mathrm{W} / \mathrm{cm}^{2}$, while the 300 $\mu \mathrm{W} / \mathrm{cm}^{2}$ irradiance produced a significantly stronger melatonin suppression than irradiances at or below $15 \mu \mathrm{W} / \mathrm{cm}^{2}$. The intermediate $17,000 \mathrm{~K}$ light irradiances of 50 and $25 \mu \mathrm{W} / \mathrm{cm}^{2}$ evoked significantly stronger melatonin suppressions than irradiances at or below $25 \mu \mathrm{W} / \mathrm{cm}^{2}$, and irradiances at or below $10 \mu \mathrm{W} / \mathrm{cm}^{2}$, respectively. Lastly, 20 $\mu \mathrm{W} / \mathrm{cm}^{2}$ elicited a stronger melatonin suppression than 10 and $1 \mu \mathrm{W} / \mathrm{cm}^{2}$; while 15 and $5 \mu \mathrm{W} / \mathrm{cm}^{2}$ produced significantly stronger suppressions than $1 \mu \mathrm{W} / \mathrm{cm}^{2}$.

Comparison of the mean pre- and post-plasma melatonin values of the SEB light exposures shows that all irradiances at or above $17.4 \mu \mathrm{W} / \mathrm{cm}^{2}$ significantly suppressed melatonin $(p<0.05$ to $p<0.005)$. For the SEB percent control-adjusted melatonin change scores, there was a significant effect of light irradiance on melatonin suppression $(F=9.43, d f=9, \quad p<0.0001)$. Increasing irradiances of $S E B$ light exposure evoked progressively larger melatonin suppressions. Fisher PLSD tests showed that the higher irradiances of SEB light (1500 and $323 \mu \mathrm{W} / \mathrm{cm}^{2}$ ) elicited significantly stronger melatonin suppression than irradiances at or below $22 \mu \mathrm{W} / \mathrm{cm}^{2}$. The corneal irradiance 58.4 $\mu \mathrm{W} / \mathrm{cm}^{2}$ elicited significantly stronger melatonin suppression than lower irradiances at or below $10 \mu \mathrm{W} / \mathrm{cm}^{2}$, while $22 \mu \mathrm{W} / \mathrm{cm}^{2}$ elicited significantly stronger melatonin suppression than irradiances at or below $6 \mu \mathrm{W} / \mathrm{cm}^{2}$. Finally, $17.4 \mu \mathrm{W} / \mathrm{cm}^{2}$ elicited significantly stronger melatonin suppression than irradiances of 6 and $4 \mu \mathrm{W} / \mathrm{cm}^{2}$.

Figure 3 shows the mean (+/- SEM) percent change control-adjusted melatonin data from the three studies presented above were plotted on a log scale of corneal irradiance along with the best-fit, sigmoidal curve. No mathematical constraints were placed on 
this family of curves. The coefficients of correlation for the $4,000 \mathrm{~K}, 17,000 \mathrm{~K}$, and SEB curves were $0.96,0.85$ and 0.95 , respectively.
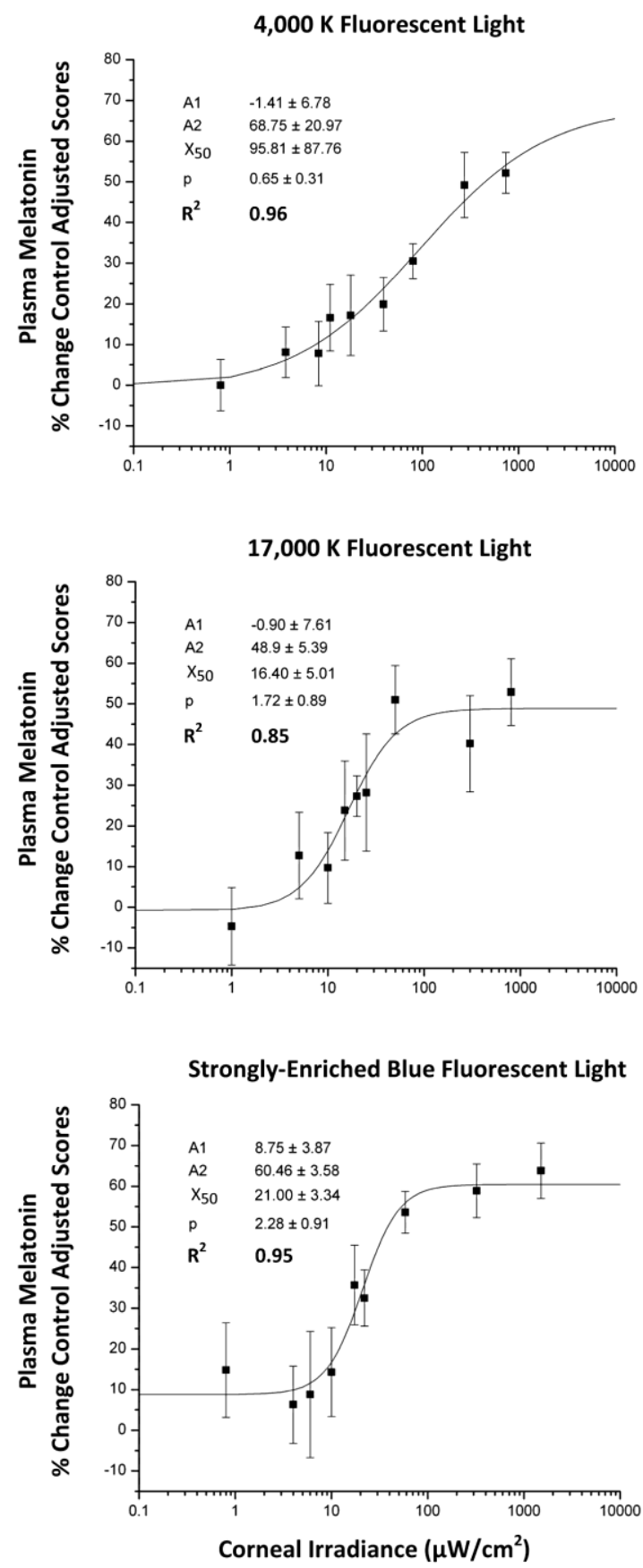

Fig. 3. Each fluence-response curve represents data collected from separate cohorts of eight healthy subjects after exposure to different types of polychromatic fluorescent light. The curve fit parameters and coefficient of correlation $\left(R^{2}\right)$ are included in the upper left portion of each graph. 
The curves illustrated in Figure 3 show that there is a progressive steepening of the slopes ( $p$ value) of the curves with greater enrichment with blue light. Further, the pseudo-linear portions of both the $17,000 \mathrm{~K}$, and SEB curves are shifted to the left in comparison to the $4,000 \mathrm{~K}$ curve. That shift is quantified by comparison of the curve's $\mathrm{X}_{50}$ parameters $(4,000 \mathrm{~K}=95.81,17,000 \mathrm{~K}=16.40$, and $\mathrm{SEB}=21.00)$. Hence, approximately six times as much light is needed to evoke a half-saturation response from the $4,000 \mathrm{~K}$ light versus the $17,000 \mathrm{~K}$ light. Similarly, approximately five times as much light is needed to evoke a half-saturation response from the $4,000 \mathrm{~K}$ light versus the SEB light.

The fluence-response curves in Figure 3 were not mathematically constrained. In action spectroscopy, it is not unusual to constrain one or more of the elements $\left(A_{1}, A_{2}\right.$, p) of the parametric model described above. Including the unconstrained curve fits in Figure 3, seven different parametric models for curve fitting the melatonin data were tested. For example, one constrained model that was tested set $A_{1}=0$. The logic of that constraint is that darkness (a corneal irradiance of 0 ) would elicit $0 \%$ melatonin suppression. The curve fits of all models all had relatively high coefficients of correlation ( $r^{2}$ ranged from 0.80 to 0.97 ). The resulting $X_{50}$ parameters resulting from application of the different models also varied in their ranges $(4,000 \mathrm{~K}=65.8$ to 95.81 , $17,000 \mathrm{~K}=9.57$ to 25.40 , and $\mathrm{SEB}=17.80$ to 22.70 ). In every case, when a single parametric model was applied across all sets of fluence-response data, the blueenriched $17,000 \mathrm{~K}$ and SEB light elicited smaller half-saturation responses compared to the $4,000 \mathrm{~K}$ light. Across these different parametric models, a range of approximately three to seven times as much irradiance is needed to evoke a half-saturation response from the $4,000 \mathrm{~K}$ light versus the $17,000 \mathrm{~K}$ light. Similarly, approximately three to five times as much light is needed to evoke a half-saturation response from the $4,000 \mathrm{~K}$ lamp versus the SEB light.

The effective rod, cone and melanopsin photoreceptor irradiances and the total irradiances and photopic illuminances were calculated as described above [36]. The 
values in Table 2 were derived from the SPDs shown in Figure 1 with photon fluxes of 9.18 or $9.19 \times 10^{14}$ photons $/ \mathrm{cm}^{2} / \mathrm{sec}$.

Table 2. Calculated irradiances, photopic illuminances $v(\lambda)$,, and human photopigment illuminances relative to three broad spectrum lights (32).

\begin{tabular}{|c|c|c|c|c|c|c|c|c|}
\hline & \multicolumn{3}{|c|}{$\begin{array}{l}\text { Radiometric and Photometric Values } \\
(380-780 \mathrm{~nm} \text { inclusive })\end{array}$} & \multicolumn{5}{|c|}{$\begin{array}{l}\text { Retinal Photopigment Weighted } \\
\text { Illuminances } \\
\text { ( } \alpha \text {-opic lux) }\end{array}$} \\
\hline & $\begin{array}{c}\text { Photon Flux } \\
\text { (photons } / \mathrm{cm}^{2} / \mathbf{s} \text { ) }\end{array}$ & $\begin{array}{l}\text { Irradiance } \\
\left(\mu \mathrm{W} / \mathrm{cm}^{2}\right)\end{array}$ & $\begin{array}{l}\text { Photopic } \\
\text { Illuminance } \\
\text { (lux) }\end{array}$ & $\begin{array}{c}\text { S } \\
\text { Cone }\end{array}$ & $\begin{array}{l}\text { Melanopsin } \\
\text { ipRGC }\end{array}$ & Rod & $\begin{array}{c}M \\
\text { Cone }\end{array}$ & $\begin{array}{c}\mathrm{L} \\
\text { Cone }\end{array}$ \\
\hline $\begin{array}{l}\text { 4,000 K } \\
\text { Light }\end{array}$ & $9.18 \mathrm{E}+14$ & 329 & 1,141 & 688 & 711 & 833 & 1,011 & 1,107 \\
\hline $\begin{array}{l}17,000 \\
\text { K Light }\end{array}$ & $9.19 E+14$ & 357 & 884 & 1,713 & 1,212 & 1,119 & 982 & 889 \\
\hline $\begin{array}{l}\text { SEB } \\
\text { Light }\end{array}$ & $9.18 E+14$ & 379 & 581 & 2,682 & 1,613 & 1,298 & 872 & 647 \\
\hline
\end{tabular}

\section{Discussion}

This study tested three types of broad spectrum fluorescent lamps that differed in their relative emission of light in the short wavelength end of the visible spectrum between 400 and $500 \mathrm{~nm}$. A hazard analysis based on national and international eye safety criteria, determined that all light exposures used in this study were safe [33,34]. The melatonin data comprise three full fluence-response relationships between graded exposures from the different types of fluorescent light and melatonin suppression in healthy humans. Comparison of the three fluence-response curves support the hypothesis that polychromatic fluorescent light is more potent for melatonin regulation when enriched in the short wavelength portion of the visible spectrum. 
Action spectroscopy is a powerful tool for revealing the underlying physiology of phototransduction. The development of fluence-response curves using monochromatic light ( $\leq 15 \mathrm{~nm}$ half-peak bandwidths) is fundamental for creating action spectra [37-39]. That approach has been used extensively for clarifying the sensitivity of neuroendocrine and circadian responses to light $[20,23,31,39,40]$. Similar to the fluence-response curves developed with monochromatic light for melatonin suppression in humans, the polychromatic fluence-reponse curves presented here have strong fits to four parameter parabolic curves $[10,11]$. There is, however, a major methodological difference between the experiments reported here versus the earlier human melatonin action spectra. Specifically, the volunteers' eyes were not pharmacologically dilated in the current studies. As shown in Table 1, the mean pupillary size varied across different irradiances and lamp types. Pupil size, in part, modifies retinal irradiance. Lighting countermeasures for circadian and sleep disruption during space exploration, as well as for individuals living on Earth, will be used when individuals have freely reactive pupils.

It is useful to compare the results reported here to two other full-range human melatonin suppression fluence-response curves in subjects with freely-reactive pupils $[41,42]$. In one study, the light stimuli were produced by narrow bandwidth blue solid-state light emitting diodes (LEDs, $469 \mathrm{~nm}$ peak, $26 \mathrm{~nm}$ half-peak bandwidth) with an exposure system identical to the one described here [41]. The calculated irradiance for a halfsaturation response $\left(X_{50}\right)$ from the blue LEDs was $14 \mu \mathrm{W} / \mathrm{cm}^{2}$ - similar to the $X_{50 S}$ of 16 and $21 \mu \mathrm{W} / \mathrm{cm}^{2}$ for the $17,000 \mathrm{~K}$ and SEB fluorescent lamps, respectively. In contrast, the $4,000 \mathrm{~K}$ lamps had a much higher $X_{50}$ of $96 \mu \mathrm{W} / \mathrm{cm}^{2}$. Together, these results indicate that blue-enriched polychromatic light elicits stronger melatonin suppression compared to equivalent intensities of light with lower emissions in the blue-appearing portion of the visible spectrum. Importantly, the data indicate that there may be limits to blue-enriching a light source for evoking stronger melatonin regulation; the halfsaturation responses from the SEB and $17,000 \mathrm{~K}$ exposures are roughly similar even though the SEB lamps emitted higher concentrations of energy in the blue portion of the spectrum compared to the $17,000 \mathrm{~K}$ lamps. 
Another study reported fluence-response curves for both phase-shifting the melatonin rhythm and suppressing nocturnal melatonin relative to cool white fluorescent light exposures [42]. The study conditions and light exposure techniques were very different from the fluence-response results discussed above. Notably, light exposures were significantly longer (390 min versus $90 \mathrm{~min}$ ). Further, subjects were adapted to an ambient illuminance of $\leq 10$ lux for 50 hours, had an 8 hour sleep opportunity in darkness, and then a 5 hour period in $\leq 10$ lux before the experimental light exposures. The resultant melatonin phase-shift and suppression fluence-response curves yielded $X_{50}$ values of 36 and $32 \mu \mathrm{W} / \mathrm{cm}^{2}$, respectively. It is likely the exposure duration and lengthy dim light/darkness adaptation contributed greatly to the differences between the $X_{50}$ value of $96 \mu \mathrm{W} / \mathrm{cm}^{2}$ relative to the $4,000 \mathrm{~K}$ data reported here. It has been shown that increasing light exposure duration from 30 to 120 min increases the melatonin suppression in human subjects [43]. Similarly, prior dim light exposure has been shown to increase the sensitivity to light in melanopsin ganglion cells in rats as well as for melatonin suppression in humans [32,44-46].

A variety of behavioral and physiological changes relative to correlated color temperature (CCT) of broad spectrum fluorescent lights have been measured [47, for review]. Generally, higher color temperature lamps emit more energy in the blue part of the visible spectrum than lower color temperature lamps [48]. Lamps with higher CCT were found to evoke a stronger melatonin suppression compared to lamps with lower CCT in healthy humans [49-51]. Additionally, compared to low CCT light, higher CCT light was observed to have a more potent effect on reducing the nocturnal fall of core temperature, decreasing body temperature change to cold challenge, and increasing the morning rise in core temperature $[50,52,53]$. Furthermore, EEG frequency has been shown to increase under high CCT as compared to lower CCT illumination [54]. Finally, a study on the effects of illumination prior to sleep showed that deep sleep was reduced under high CCT compared to low CCT during the first half of sleep [55]. This composite literature consistently demonstrates that higher CCT light induces stronger acute neuroendocrine and neurobehavioral effects than lower CCT light in healthy subjects. Those findings are generally consistent with the analytical action spectra that 
demonstrate the blue-appearing portion of the visible spectrum is more potent for circadian, neuroendocrine and neurobehavioral regulation.

Only three studies have compared cool white fluorescent light versus blue-enriched fluorescent light $(17,000 \mathrm{~K})$ for phase-shifting the circadian system in humans. Two studies compared equal photon fluxes of $4,100 \mathrm{~K}$ versus $17,000 \mathrm{~K}$ light for phasedelaying or phase-advancing dim light melatonin onset (DLMO) $[56,57]$. Both studies showed that each type of light elicited strong DLMO phase-shifts with no significant difference between groups. Those studies used relatively high, potentially saturating, light levels that are commonly used for evoking phase-shifts $\left(4.2 \times 10^{15}\right.$ photons $/ \mathrm{cm}^{2} / \mathrm{sec}$, or $5,000-4,000 \mathrm{lux}$ ). A third study compared equal photon doses of lower light levels ( $1 \times 10^{14}$ photons $/ \mathrm{cm}^{2} / \mathrm{s}$ or $134-129$ lux) of $4,000 \mathrm{~K}$ versus $17,000 \mathrm{~K}$ light for eliciting a DLMO phase-delay in healthy subjects [58]. Although the $17,000 \mathrm{~K}$ light caused a greater mean phase-delay shift of 2.1 hours compared to $4,000 \mathrm{~K}$ light that elicited a 1.7 delay, the difference was not statistically significant. These studies indicate that blue-enriched fluorescent light has greater potency for eliciting acute biological and behavioral responses but longer term effects like circadian phase-shifting does not reflect that same sensitivity. Further research is needed to clarify such differences between short and long term effects of polychromatic light.

Measured radiometric and photometric values for the studies' lighting stimuli are provided in Figure 1 and Table 1. Currently, there is not a standardized, single measurement unit available for quantifying light that regulates the circadian, neuroendocrine and neurobehavioral effects of light. A recent consensus position was developed across many of the laboratories that have studied wavelength regulation of the biological and behavioral effects of light in humans and other species for best practices for measuring and reporting light stimuli [36]. With that consensus, a freely available web-based toolbox was provided that permits calculation of the effective irradiance for each of the human ipRGC, cone and rod photoreceptors that are capable of driving physiological effects [36]. Table 2 provides the computed effective photoreceptor illuminances of the three polychromatic lights used in this study. Such 
data are intended for making comparisons of polychromatic lights of different spectral quality significantly more traceable [36].

Examining the calculated photoreceptor illuminances, it is clear that lamplight that is progressively enriched with short wavelengths is predicted to have increasingly higher S cone, melanopsin ipRGC, and rod weighted illuminances. Conversely, those same lamplights have progressively lower $M$ cone and $L$ cone weighted illuminances. Given that the $\mathrm{ED}_{50}$ for melatonin suppression of both $17,000 \mathrm{~K}$ and SEB lamplight were five times smaller than that of the $4,000 \mathrm{~K}$ lamplight, the empirical melatonin suppression data support the hypothesis that polychromatic light with increased emissions of short wavelengths has increased potency for acute regulation of the pineal gland. The melatonin data, however, suggest that there are limits to increasing potency of light with short wavelengths as the SEB light did not have an ED 50 lower than the 17,000 K light.

Although it would be desirable to use a single unit for quantifying light that elicits circadian, neuroendocrine, and neurobehavioral responses ,this is not currently feasible. Abundant evidence shows that the melanopsin ipRGCs are anatomically and functionally interconnected with the rods and cones that support vision [20,27$32,36,40,59,60]$. Light-induced physiological responses reflect input from all of the retinal photoreceptor classes, with the relative importance of each being highly labile within and between response types. Consequently, the spectral sensitivity of this photoreceptive system is fundamentally context-dependent $[15,17,20,29$ $32,36,40,59,60]$.

The lack of a consistent and adequate method of quantifying light makes it challenging to replicate experimental conditions or to compare across studies. For this nascent field of research to mature, different groups of investigators need to use commonly accepted metrics for reporting spectral response functions to be able to pool results such as those shown in Table 2. As published data using this measurement system accumulate, it will then be possible to generate testable hypotheses that predict the spectral characteristics for a targeted physiological or behavioral response to light. 
There are limitations to the data presented here. First, each study employed young adults. Results from studies with older adults would differ significantly due to agerelated differences such as ocular media transmission [61,62]. Second, although each fluence-response curve was developed with a complete within-subjects study design, three separate cohorts of subjects were studied. An ideal comparison of the potency across three lamplights would have employed the same subjects for all three curves. That is logistically challenging, however, due to subject compliance and drop out. No published human neuroendocrine studies yet have provided three full-range fluenceresponse curves within a single subject cohort. Finally, the light exposure technique involved constant $90 \mathrm{~min}$ full retinal field exposures. Such exposures are optimum for comparing the potency of the three types of lamplight. When used in daily applications such as the home, workplace or spaceflight environments, exposure conditions rarely would be full retinal field or continuous. Studies in a variety of architecturally illuminated spaces are needed to define the optimum illuminances and irradiances that support vision as well as the biological and behavioral efficacy of built-in lighting.

Risks for the health and safety of astronauts and ground control workers include disturbed circadian rhythms and sleep loss. Such problems may cause impaired alertness, loss of concentration, and diminished performance $[5,6,63,64]$. The broader research goal was to determine the best combination of wavelengths for a lighting countermeasure for circadian and sleep disruption during space exploration, and individuals on Earth. The data presented here provide a first step towards that aim. NASA has used high illuminances of white fluorescent light as a pre-launch countermeasure for circadian disruption in astronauts [5]. Solid-state lighting now provides the potential to provide astronauts light therapy during spaceflight. The retrofit of the International Space Station (ISS) fluorescent lighting system to solid-state lighting is scheduled to begin in 2016 [65]. A recent study on the Mars Phoenix Lander ground crew demonstrated that a blend of countermeasures including exposure to blue solidstate light effectively improved alertness and circadian entrainment [6]. Initial tests of have probed the ISS lighting system's capacity for supporting astronaut vision and 
regulating melatonin [66]. Lighting countermeasures are promising for general domestic use in architectural applications or clinically, such as treating specific circadian disorders. Results from two field studies testing 17,000 K fluorescent lamps in the work places indicate that this lamplight improved employee alertness and well being $[67,68]$. Now the door is open to future lighting designs of building interiors that address the traditional lighting values along with fostering benefits to human health and well being.

\section{Acknowledgments}

Research support came from the National Space Biomedical Research Institute through NASA NCC 9-58. We are grateful for the support of Gerrit van den Beld, Luc Schlangen, Ph.D., and George Kok of Philips Lighting in providing the study lamps and ballasts. We appreciate the assistance of David H. Sliney, Ph.D., who performed the light source hazard analyses as a consultant. We are grateful to Steve Lockley, Ph.D., Rob Lucas, Ph.D., Stuart Peirson, Ph.D., Luke Price, Ignacio Provencio, Ph.D., and Jamie Zeitzer, Ph.D., for discussions and insights related to these studies. We thank Edward Gerner, M.D., Bill Coyle, Michael Jablonski, Ph.D., Kate Cecil, Erin Martin, Katherine West, Jessica Ricker, Brandice Durkan, M.D., and Matthew Isenberg for their invaluable assistance in completing this research. In addition, we thank Kareema Brown, Tyisha Vincent, Karen White, and Marianne Hamel Ph.D., for phlebotomy support.

\section{Author Contributions}

George Brainard and John Hanifin were responsible for study design, data acquisition, analysis, and interpretation, as well as the original manuscript draft. Benjamin Warfield, Marielle Stone, Mary James, Melissa Ayers, Alan Kubey, Brenda Byrne, and Mark Rollag were each involved in data acquisition, analysis and interpretation, as well as critical manuscript revision. All authors have approved the submitted version of the manuscript. 


\section{References}

1. COMMISSION INTERNATIONALE DE L'ECLAIRAGE Ocular Lighting Effects on Human Physiology and Behaviour. In, Technical Report \#158, Commission Internationale de l'Eclairage, Vienna, 2004; pp. 1-54.

2. SPECIAL ISSUE: Human circadian rhythms: regulation and impact. J Biol Rhythms 2005; 20:279-386.

3. ILLUMINATING ENGINEERING SOCIETY OF NORTH AMERICA. Light and Human Health: An Overview of the Impact of Optical Radiation on Visual, Circadian, Neuroendocrine, and Neurobehavioral Responses, IES TM-18-08. In, Illuminating Engineering Society of North America, New York, 2008; pp. 1-23.

4. LAM RW, LEVITT AJ. Canadian Consensus Guidelines for the Treatment of Seasonal Affective Disorder. In, Clinical and Academic Publishing, Vancouver, British Columbia, 1999.

5. CZEISLER CA, CHIASERA AJ 5, DUFFY JF Research on sleep, circadian rhythms and aging: applications to manned spaceflight. Exp Gerontol 1991; 26:217232.

6. BARGER LK, SULLIVAN JP, VINCENT AS et al. Learning to live on a Mars day: fatigue countermeasures during the Phoenix Mars Lander mission. Sleep 2012; 35:1423-1435.

7. MOORE RY. Organization and function of a central nervous system circadian oscillator: the suprachiasmatic hypothalamic nucleus. Fed Proc 1983; 42:2783-2789.

8. REITER RJ Pineal melatonin: cell biology of its synthesis and of its physiological interactions. Endocr Rev 1991; 12:151-180.

9. LEWY AJ, WEHR TA, GOODWIN FK et al. Light suppresses melatonin secretion in humans. Science 1980; 210:1267-1269.

10. BRAINARD GC, HANIFIN JP, GREESON JM et al. Action spectrum for melatonin regulation in humans: evidence for a novel circadian photoreceptor. $\mathrm{J}$ Neurosci 2001; 21:6405-6412.

11. THAPAN K, ARENDT J, SKENE DJ An action spectrum for melatonin suppression: evidence for a novel non-rod, non-cone photoreceptor system in humans. J Physiol 2001; 535:261-267.

12. LIU C, WEAVER DR, JIN X et al. Molecular dissection of two distinct actions of melatonin on the suprachiasmatic circadian clock. Neuron 1997; 19:91-102. 
13. LEGROS C, CHESNEAU D, BOUTIN JA et al. Melatonin from cerebrospinal fluid but not from blood reaches sheep cerebral tissues under physiological conditions. J Neuroendocrinol 2014; 26:151-163.

14. REITER RJ, TAN DX, KIM SJ et al. Delivery of pineal melatonin to the brain and SCN: role of canaliculi, cerebrospinal fluid, tanycytes and Virchow-Robin perivascular spaces. Brain Struct Funct 2014; 219:1873-1887.

15. LOCKLEY SW, BRAINARD GC, CZEISLER CA High sensitivity of the human circadian melatonin rhythm to resetting by short wavelength light. J Clin Endocrinol Metab 2003; 88:4502-4505.

16. CAJOCHEN C, MUNCH M, KOBIALKA S et al. High sensitivity of human melatonin, alertness, thermoregulation, and heart rate to short wavelength light. J Clin Endocrinol Metab 2005; 90:1311-1316.

17. LOCKLEY SW, EVANS EE, SCHEER FA et al. Short-wavelength sensitivity for the direct effects of light on alertness, vigilance, and the waking electroencephalogram in humans. Sleep 2006; 29:161-168.

18. REVELL VL, ARENDT J, FOGG LF et al. Alerting effects of light are sensitive to very short wavelengths. Neurosci Lett 2006; 399:96-100.

19. ZAIDI FH, HULL JT, PEIRSON SN et al. Short-wavelength light sensitivity of circadian, pupillary, and visual awareness in humans lacking an outer retina. Curr Biol 2007; 17:2122-2128.

20. GOOLEY JJ, RAJARATNAM SM, BRAINARD GC et al. Spectral responses of the human circadian system depend on the irradiance and duration of exposure to light. Sci Transl Med 2010; 2:31ra33.

21. RUGER M, ST. HILAIRE MA, BRAINARD GC et al. Human phase response curve to a single 6.5h light pulse of short-wavelength light. J Physiol 2013; 591:353-363.

22. RAHMAN SA, FLYNN-EVANS EE, AESCHBACH D et al. Diurnal spectral sensitivity of the acute alerting effects of light. Sleep 2014; 37:271-281.

23. BERSON DM, DUNN FA, TAKAO M Phototransduction by retinal ganglion cells that set the circadian clock. Science 2002; 295:1070-1073.

24. HATTAR S, LIAO H-W, TAKAO M et al. Melanopsin-containing retinal ganglion cells: architecture, projections, and intrinsic photosensitivity. Science 2002; 295:10651070.

25. PROVENCIO I, ROLLAG MD, CASTRUCCI AM Photoreceptive net in the mammalian retina. Nature 2002; 415:493. 
26. PROVENCIO I, RODRIGUEZ IR, JIANG G et al. A novel human opsin in the inner retina. J Neurosci 2000; 20:600-605.

27. PANDA S, PROVENCIO I, TU DC et al. Melanopsin is required for non-imageforming photic responses in blind mice. Science 2003; 301:525-527.

28. HATTAR S, LUCAS RJ, MROSOVSKY N et al. Melanopsin and rod-cone photoreceptive systems account for all major accessory visual functions in mice. Nature 2003; 424:76-81.

29. LALL GS, REVELL VL, MOMIJI H et al. Distinct contributions of rod, cone, and melanopsin photoreceptors to encoding irradiance. Neuron 2010; 66:417-428.

30. ALTIMUS CM, GULER AD, ALAM NM et al. Rod photoreceptors drive circadian photoentrainment across a wide range of light intensities. Nat Neurosci 2010; 13:11071112.

31. DACEY DM, LIAO H-W, PETERSON BB et al. Melanopsin-expressing ganglion cells in primate retina signal colour and irradiance and project to the LGN. Nature 2005; 433:749-754.

32. JASSER SA, HANIFIN JP, ROLLAG MD et al. Dim light adaptation attenuates acute melatonin suppression in humans. J Biol Rhythms 2006; 21:394-404.

33. AMERICAN CONFERENCE OF GOVERNMENTAL INDUSTRIAL HYGIENISTS. Light and near-infrared radiation. In: Documentation of the Threshold Limit Values and Biological Exposure Indices, American Conference of Governmental Industrial Hygienists, Cincinnati, Ohio, 2010; pp. 134-141.

34. INTERNATIONAL COMMISSION ON NON-IONIZING RADIATION PROTECTION. Guidelines on limits of exposure to broad-band incoherent optical radiation (0.38 to 3 microM). Health Phys 1997; 73:539-554.

35. ROLLAG MD, NISWENDER GD Radioimmunoassay of serum concentrations of melatonin in sheep exposed to different lighting regimens. Endocrinology 1976; 98:482489.

36. LUCAS RJ, PEIRSON SN, BERSON DM et al. Measuring and using light in the melanopsin age. Trends Neurosci 2014; 37:1-9.

37. LIPSON ED. Action spectroscopy: methodology. In: Organic Photochemistry and Photobiology. Horspool Wm , Song P-S eds., CRC Press, New York, 1994; pp. 1257-1266. 
38. COOHILL TP. Photobiological action spectra- what do they mean? In: Measurements of Optical Radiation Hazards. Matthes R, Sliney D, Didomenico S, et al. eds., ICNIRP, Munchen, Germany, 1999; pp. 27-39.

39. BRAINARD GC, HANIFIN JP Photons, clocks and consciousness. J Biol Rhythms 2005; 20:314-325.

40. GAMLIN PDR, MCDOUGAL DH, POKORNY $\mathrm{J}$ et al. Human and macaque pupil responses driven by melanopsin-containing retinal gangion cells. Vision Res 2007; 47:946-954.

41. WEST KE, JABLONSKI MR, WARFIELD B et al. Blue light from light-emitting diodes (LEDs) elicits a dose-dependent suppression of melatonin in humans. J Appl Physiol 2011; 110:619-626.

42. ZEITZER JM, DIJK D-J, KRONAUER RE et al. Sensitivity of the human circadian pacemaker to nocturnal light: melatonin phase resetting and suppression. J Physiol 2000; 526:695-702.

43. AOKI H, YAMADA N, OZEKI $Y$ et al. Minimum light intensity required to suppress nocturnal melatonin concentration in human saliva. Neurosci Lett 1998; 252:91-94.

44. HEBERT M, MARTIN SK, LEE C et al. The effects of prior light history on the suppression of melatonin by light in humans. J Pineal Res 2002; 33:198-203.

45. WONG KY, DUNN FA, BERSON DM Photoreceptor adaptation in intrinsically photosensitive retinal ganglion cells. Neuron 2005; 48:1001-1010.

46. CHANG A-M, SCHEER FA, CZEISLER CA The human circadian system adapts to prior photic history. J Physiol 2011; 589:1095-1102.

47. HANIFIN JP, BRAINARD GC Photoreception for circadian, neuroendocrine and neurobehavioral regulation. J Physiol Anthropol Appl Human Sci 2007; 26:87-94.

48. DILAURA DL, HOUSER KW, MISTRICK RG et al. Lighting Handbook. Tenth Edition: Reference and Application. In. Dilaura DI, Houser Kw, Mistrick Rg, et al. eds., Illuminating Engineering Society of North America, New York, 2011.

49. MORITA T, TOKURA H The influence of different wavelengths of light on human biological rhythms. Appl Human Sci 1998; 17:91-96.

50. SATO M, SAKAGUCHI T, MORITA T The effects of exposure in the morning to light of different color temperatures on the behavior of core temperature and melatonin secretion in humans. Biol Rhythm Res 2005; 36:278-292. 
51. KOZAKI T, KOGA S, TODA $\mathrm{N}$ et al. Effects of short wavelength control in polychromatic light sources on nocturnal melatonin secretion. Neurosci Lett 2008; 439:256-259.

52. MORITA T, TOKURA H Effects of lights of different color temperature on the nocturnal changes in core temperature and melatonin in humans. Appl Human Sci 1996; 15:243-246.

53. YASUKOUCHI A, YASUKOUCHI Y, ISHIBASHI K Effects of color temperature of fluorescent lamps on body temperature regulation in a moderately cold environment. J Physiol Anthropol Appl Human Sci 2000; 19:125-134.

54. NOGUCHI H, SAKAGUCHI T Effect of illuminance and color temperature on lowering of physiological activity. Appl Human Sci 1999; 18:117-123.

55. KOZAKI T, KITAMURA S, HIGASHIHARA Y et al. Effect of color temperature of light sources on slow-wave sleep. J Physiol Anthropol Appl Human Sci 2005; 24:183186.

56. SMITH MR, EASTMAN CI Phase delaying the human circadian clock with blueenriched polychromatic light. Chronobiol Int 2009; 26:709-725.

57. SMITH MR, REVELL VL, EASTMAN CI Phase advancing the human circadian clock with blue-enriched polychromatic light. Sleep Med 2009; 10:287-294.

58. HANIFIN J, LOCKLEY S, CECIL K et al. Polychromatic blue-enriched fluorescent light for melatonin suppression and circadian phase resetting. In, 21st Annual Meeting of the Society for Light Treatment and Biological Rhythms, Berlin, Germany, June 2427, 2009.

59. ECKER JL, DUMITRESCU ON, WONG KY et al. Melanopsin-expressing retinal ganglion-cell photoreceptors: cellular diversity and role in pattern vision. Neuron 2010; 67:49-60.

60. WENG S, ESTEVEZ ME, BERSON DM Mouse ganglion-cell photoreceptors are driven by the most sensitive rod pathway and by both types of cones. PLoS ONE 2013; 8:e66480.

61. POKORNY J, SMITH VC, LUTZE M Aging of the human lens. Appl Optics 1987; 26:1437-1440.

62. BRAINARD GC, ROLLAG MD, HANIFIN JP Photic regulation of melatonin in humans: ocular and neural signal transduction. J Biol Rhythms 1997; 12:537-546. 
63. BARGER LK, FLYNN-EVANS EE, KUBEY A et al. Prevalence of sleep deficiency and use of hypnotic drugs in astronauts before, during, and after spaceflight: an observational study. Lancet Neurol 2014; 13:904-912.

64. WHITMIRE AM, LEVETON LB, BARGER $L$ et al. Risk of performance errors due to sleep loss, circadian desynchronization, fatigue, and work overload. In: Human Health and Performance Risks of Space Exploration Missions. Mcphee Jc , Charles Jb eds., NASA, Johnson Space Center, Houston, 2010; pp. 85-116.

65. NATIONAL AERONAUTICS AND SPACE ADMINISTRATION. ISS Interior Solid State Lighting Assembly (SSLA) Specification, Revision C, May 2013, S684-13489. In, Johnson Space Center, Houston, Texas, 2013; pp. 1-60.

66. BRAINARD GC, COYLE W, AYERS $M$ et al. Solid-state lighting for the International Space Station: tests of visual performance and melatonin regulation. Acta Astronautica 2013; 92:21-28.

67. MILLS PM, TOMKINS SC, SCHLANGEN LJM The effect of high correlated colour temperature office lighting on employee wellbeing and work performance. $J$ Circad Rhythms 2007; 5:2-10.

68. VIOLA AU, L.M. J, SCHLANGEN LJM et al. Blue-enriched white light in the workplace improves self-reported alertness, performance and sleep quality. Scand $\mathrm{J}$ Work Environ Health 2008; 34:297-306.

\section{Figure Legends}

1. These graphs show the spectral power distribution (SPD) of the polychromatic light sources. The top SPD is from a standard white fluorescent lamp $(4,000 \mathrm{~K} \mathrm{CCT})$. The middle SPD graph is from a prototype white-appearing, blue-enriched lamp $(17,000 \mathrm{~K}$ CCT). The bottom SPD is from a prototype strongly enriched blue (SEB) lamp.

2. The top graph compares the mean (+ SEM) pre- and post-plasma melatonin values for the $4,000 \mathrm{~K}$ light exposures. Percent control-adjusted melatonin change scores from these data are presented in the bottom graph. 
3. Each fluence-reponse curve represents data collected from separate cohorts of 8 healthy subjects after exposure to different types of polychromatic fluorescent light. The curve fit parameters and coefficient of correlation $\left(R^{2}\right)$ are included in the upper left portion of each graph. 